\title{
14
}

\section{Strategies for prevention and mitigation of hay fever}

\author{
M.F. Schenk ${ }^{\#}$, A.J.H. van Vliet ${ }^{\# \#, ~ M . J . M . ~ S m u l d e r s ~}{ }^{\#}$, L.J.W.J. Gilissen ${ }^{\#, *}$
}

\begin{abstract}
Seasonal allergic rhinitis is a widespread disorder in westernized countries. It has a strong negative impact on the patient's health-related quality of life and is accompanied by considerable medical and economic costs. Currently, the socioeconomic interest in prevention is growing. Reducing or avoiding allergen exposure may result in a significant reduction of sensitization and mitigation of allergic complaints, and this reduction is in addition to existing medical prevention strategies. It will require good communication to (potential) patients on the importance and possibilities for reducing the contact with allergenic pollen. Longterm pollen monitoring and forecasts of the flowering period of allergenic plants are important tools in this respect. Reducing the allergenic load may prove an alternative prevention strategy. Pollen sources are heterogeneously distributed throughout the landscape and may be avoided or selectively removed. The use of selection, conventional breeding strategies or genetic modification may reduce the allergenicity of the pollen sources. Strategies that involve genetic modification are, however, likely to raise some public concern and acceptability of these strategies has to be considered. Keywords: seasonal allergic rhinitis; allergy prevention; pollen allergens; crossreactivity; phenology; allergenicity; risk analysis; public concern
\end{abstract}

\section{Introduction}

The prevalence of allergic complaints like atopic dermatitis, allergic rhinitis and allergic asthma has strongly increased during the last decades (Aberg et al. 1995; Strachan 1989; Wüthrich et al. 1995). This increase was most profound in westernized countries. Especially seasonal allergic rhinitis (SAR, hay fever) holds a prominent place, also because of its link to the oral-allergy syndrome (OAS) (Wensing et al. 2002). Allergic rhinitis has a negative impact on the patient's health-related quality of life. Besides the obvious clinical effects, it is accompanied by fatigue, irritations and loss of sleep and concentration (Meltzer 2001). These may lead to a decreased cognitive functioning and learning impairment in children in the long term. SAR is associated with both considerable direct and indirect costs that result from medical treatment and the loss of school and working days. In Europe alone, the total annual costs for allergic rhinitis are estimated at 3 billion Euros in 1997 (UCB 1997). When extrapolating these costs to 2004, this results in 3.7 billion Euros of annual costs, while the estimates for the USA amount to 4.9 billion Dollars (Schoenwetter et al.

\footnotetext{
${ }^{\text {\# }}$ Plant Research International, P.O. Box 16, 6700 AA Wageningen, The Netherlands

\#\# Environmental Systems Analysis Group, Wageningen University, P.O. Box 47, 6700 AA Wageningen, The Netherlands

*Corresponding author. E-mail: luud.gilissen@wur.nl
} 
2004). The development of efficient prevention strategies has, therefore, a clear socioeconomic interest, for both individual patients and the society in general. In this paper we focus on prevention and mitigation strategies that will decrease the allergen exposure in the direct environment of the patient. This should lead to both a lower occurrence of sensitization and mitigation of allergic complaints.

\section{Hay fever: cause and effect}

\section{Sensitization and symptoms}

An allergic reaction is preceded by a sensitization phase, in which a T-cell response eventually leads to the production of an $\operatorname{IgE}$ that is specific for a particular protein. The IgE is bound to receptors on the surface of mast cells. Upon renewed allergen contact, the allergenic protein binds to this specific IgE. The mast cells release large amounts of histamine, causing the clinical symptoms. In the case of hay fever, this results in sneezing, rhinorrhoea and a blocked nose, often accompanied by complaints such as itchy eyes (conjunctivitis), throat and ears. Diagnosing hay fever is somewhat ambiguous, because of the similarities with non-atopic complaints and a lack of standardized methodology. The disorder can be defined on pathophysiological characteristics (the detection of specific IgE by a positive RAST or skin prick test) or on symptom criteria, but the combination of the two results in the most reliable diagnosis (UCB 1997).

Sensitization to pollen allergens and hay-fever symptoms may start developing as early as at the age of two (Kulig et al. 2000). Sensitization to pollen is relatively low in young children (Silvestri et al. 1996), while sensitization to mite allergens, which may result in the development of perennial allergic rhinitis, already has a high prevalence by then. Sensitization to pollen increases with age (Silvestri et al. 1996), in concordance with the prevalence of respiratory allergies, which peaks among young adults (Saarinen and Kajosaari 1995). The pollen that cause hay fever complaints continue to be problematic in later stages of life; there is a positive correlation between daily pollen concentrations in the air and mortality (Brunekreef et al. 2000). Treatment of symptoms is possible by the administration of anti-histamine, $\beta_{2-}$ agonists, corticosteroids and mast-cell stabilizing medication. Long-term treatment can be achieved by immunotherapy in some patients. The patient's sensitivity is then decreased by the repetitive and controlled administration of increasing doses of a specific allergen.

\section{Pollen sources}

Hay fever symptoms are experienced periodically, during the pollen season of the plant species to which the patients are sensitized. Wind-pollinating species produce huge amounts of pollen. Birch trees, for example, are abundant pollen producers and if weather conditions are favourable this may lead to peak values of over 2,000 pollen grains per $\mathrm{m}^{3}$ per day (Latalowa, Mietus and Uruska 2002; Weryszko-Chmielewska, Puc and Rapiejko 2001). For The Netherlands, we can partition the wind pollinators that produce allergens in three groups:

- Trees, mainly Fagales trees like birch (Betula pendula), alder (Alnus glutinosa), and hazel (Corylus avellana), in which the main allergen is a pathogenesis-related (PR-) 10 protein (Breiteneder et al. 1989; 1992; 1993), which cross-reacts with homologous proteins in several fruits, nuts and vegetables (Table 1). 
- Grasses, several species including rye grass (Lolium perenne), orchard grass (Dactylis glomerata) and timothy grass (Phleum pratense), in which the main allergens are the Lol p 1 and Lol p 5 variants (Bond et al. 1993).

- Weeds, like mugwort (Artemisia vulgaris), plantain (Plantago lanceolata), sorrel (Rumex sp.), and nettle (Urtica sp.). This is a mixed group with several crossreacting allergens (Asero et al. 2000; Hirschwehr et al. 1998).

Table 1. Examples of cross-reactivity between pollen and food allergens

\begin{tabular}{|c|c|c|}
\hline Protein type & Pollen source (allergen) & Food (allergen) \\
\hline \multirow[t]{4}{*}{ PR-10 } & \multirow{4}{*}{$\begin{array}{l}\text { Birch, Betula pendula (Bet v } \\
\text { 1) }\end{array}$} & Apple (Mal d 1) (Fritsch et al. 1998) \\
\hline & & Celery (Api g 1) (Bohle et al. 2003) \\
\hline & & $\begin{array}{l}\text { Hazelnut (Cor a 1) (Lüttkopf et al. } \\
\text { 2002) }\end{array}$ \\
\hline & & $\begin{array}{l}\text { Cherry (Pru av 1) (Scheurer et al. } \\
\text { 1999) }\end{array}$ \\
\hline \multirow[t]{3}{*}{ Profilin } & Grass, Poaceae (e.g. Lol p 12) & $\begin{array}{l}\text { Tomato (Lyc e 1) (Westphal et al. } \\
\text { 2004) }\end{array}$ \\
\hline & Plane tree, Platanus acerifolia & $\begin{array}{l}\text { Hazelnut (Cor a 2), Peanut (Ara h 5), } \\
\text { Banana (Mus xp 1), Celery (Api g 4) } \\
\text { (Miralles et al. 2002) }\end{array}$ \\
\hline & $\begin{array}{l}\text { Birch, Betula pendula (Bet v } \\
\text { 2) }\end{array}$ & $\begin{array}{l}\text { Hazelnut (Cor a 2) (Hirschwehr et al } \\
\text { 1992) }\end{array}$ \\
\hline 60kDa allergen & $\begin{array}{l}\text { Mugwort, Artemisia vulgaris } \\
\text { (Art v 1) }\end{array}$ & $\begin{array}{l}\text { Apple, Kiwi, Celery (Api g 5) (Heiss } \\
\text { et al. 1996) }\end{array}$ \\
\hline PCBER & $\begin{array}{l}\text { Birch, Betula pendula (Bet v } \\
6)\end{array}$ & Pear (Pyr c 5) (Karamloo et al. 2001) \\
\hline
\end{tabular}

Each group has a different flowering period. The tree pollen season may start as early as January when alder and hazel trees flower, and shows a peak in April-May when birch trees flower. The main flowering period for grass is in June-July, and an allergic reaction to weed pollen may be experienced throughout the summer.

\section{Associated complaints}

Several allergic disorders are closely linked to hay fever. For example, 13-38\% of the allergic rhinitis patients suffer from allergic asthma, and hay fever is sometimes considered to act as a gate opener to asthma (Meltzer 2001). Rhinosinusitis and otitis media are also linked to hay fever. The connection between hay fever and food allergy has recently received much attention. Several allergenic pollen proteins have homologous proteins in fruits and vegetables. Specific IgE to pollen allergens may subsequently cross-react to these food proteins (Ferreira et al. 2004). Approximately $50-70 \%$ of the hay-fever patients suffer from one or several food allergies and display symptoms upon the ingestion of fresh fruit from members of the Rosaceae family, like apple, cherry, peach and plum, but also celery and carrot (Table 1). Especially patients who are sensitized to birch pollen are prone to develop food allergy, since the pollen allergen initiates the sensitization to the main allergens in apple and celery (Bohle et al. 2003; Ferreira et al. 2004; Fritsch et al. 1998). For example, 73\% of the patients who are sensitized to the major birch allergen Bet $\mathrm{v} 1$ are also reacting to a natural apple extract (Rossi, Monasterolo and Monasterolo 2003). Much attention to this is paid in a large European research project (EU-SAFE, http://www.akh- 
wien.ac.at/safe/), in which institutes from the fields of medicine, food research and plant breeding participate in co-operation with partners from the food industry and the European allergy-patient organization (EFA). Hay-fever-associated food allergies lead to allergic reactions like an itchy or burning sensation of the palate, often combined with mucosal swelling, angio-oedema, nausea, vomiting or rhinitis. These symptoms make up the oral-allergy syndrome (OAS), which is generally not life-threatening.

\section{Prevalence and risk factors}

\section{Increasing prevalence}

Studies in several West-European countries have estimated that the prevalence of hay fever is within the range of 10.9 to $18.6 \%$ (UCB 1997). This is comparable to the USA, where the prevalence is estimated to be between 10 and $30 \%$ in adults and $40 \%$ in children. Prevalence estimates vary, depending on the type of study and the diagnostic criteria. Because not every patient consults a physician, the prevalence is often underestimated in research that is based on patient counting. Self-reporting of the symptoms tends to overestimate the prevalence because of similarities with nonatopic complaints. The use of objective markers like skin prick tests and RAST is less suitable for estimating the prevalence of hay fever, because not every sensitized person develops actual symptoms. Even with this inherent variation in the estimates, the prevalence of hay fever has shown a strong increase during the last century, which has been recorded extensively in e.g. Switzerland (Table 2). This increase may be explained only partly by the fact that an increasing number of patients are prompted to search medical treatment by the increased publicity that surrounds allergy.

Table 2. Prevalence of allergic rhinitis in Switzerland (taken from Wüthrich et al. 1995)

\begin{tabular}{|l|l|}
\hline Year & Prevalence (in \%) \\
\hline 1926 & 0.82 \\
1958 & 4.8 \\
1985 & 9.6 \\
$1991-1993$ & 13.5 \\
\hline
\end{tabular}

\section{Anthropogenic risk factors}

A history of atopy in the family has been identified as an important risk factor in several cross-sectional studies (Jõgi et al. 1998; Rönmark et al. 2003), and the development of atopy has a clear genetic basis. Whether sensitization to pollen allergens and subsequent hay-fever symptoms develop, depends also on several adjuvant and exposure-related factors. Figure 1 summarizes this.

Several socioeconomic factors that relate to an increased affluence, such as lifestyle (Alm et al. 1999), an increasing use of antibiotics and vaccination (Alm et al. 1997) and a decreasing family size (Von Mutius et al. 1994), also correlate with an increased prevalence of allergies. This observation has lead to the formation of the hygiene hypothesis (Strachan 1989), which proposes that an increased affluence has lead to an increased hygiene and reduced exposure of the immune system to microbes (Krause et al. 2002). This would induce an immune system that is skewed towards a $\mathrm{T}_{\mathrm{H}} 2$ response and consequently has a reduced tolerance for proteins that would 


\section{Allergy: Development $(\rightarrow)$ and Prevention $(\rightarrow)$}

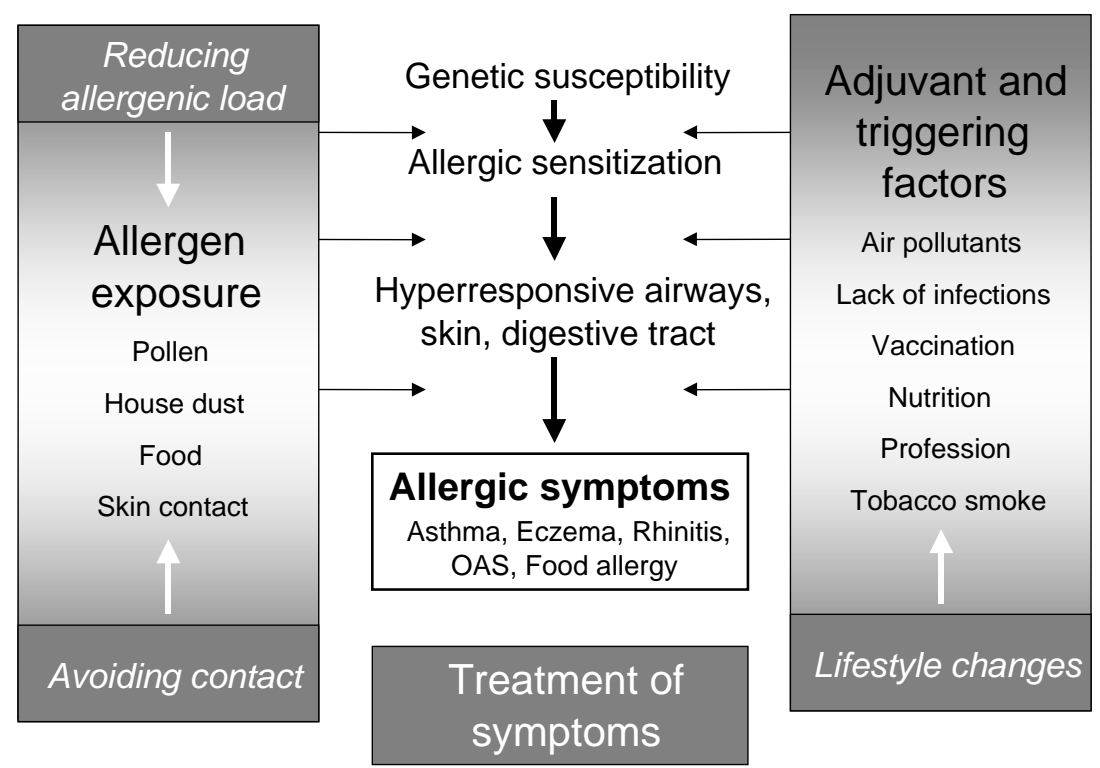

Figure 1. Several factors influence the development of allergic symptoms, which also creates various opportunities for prevention

otherwise not cause an immune reaction. It has recently been suggested that it is actually the absence of regulatory T-cells, due to a low pathogen and parasite burden, that causes the imbalance (Yazdanbakhsh, Kremsner and Van Ree 2002). The hygiene hypothesis also explains differences in the prevalence of allergies between people with a childhood on a farm and people with a non-farm childhood. The increased contact to microbes in the farm environment would, in that view, result in the reduced prevalence of hay fever (Portengen et al. 2002; Riedler et al. 2000). The hygiene hypothesis does not, however, explain all the differences in prevalence between countries and regions. The degree of urbanization, lifestyle in general and ethnical background may all be involved. Other potential risk factors are the exposure to air pollution caused by exhaust gasses (Lee et al. 2003) or to tobacco smoke (Hjern et al. 2001).

\section{Natural risk factors}

Natural risk factors are strongly involved in the development of allergic disorders. The plant species to which sensitization occurs vary between different European regions, depending on vegetation composition, which in turn depends on climate (D'Amato et al. 1998). The exposure to pollen is influenced by variation in the length of the pollen season and meteorological conditions. These vary year by year, taking into account that the length of the pollen season also depends on climatic fluctuations and climatic changes. Wind-pollinated species in The Netherlands flowered almost three weeks longer between 1990 and 2000 than during the period 1977-1987. Especially the start of the pollen season has, on average, advanced by two weeks as a result of a higher average temperature (Figure 2) (Van Vliet et al. 2002). 


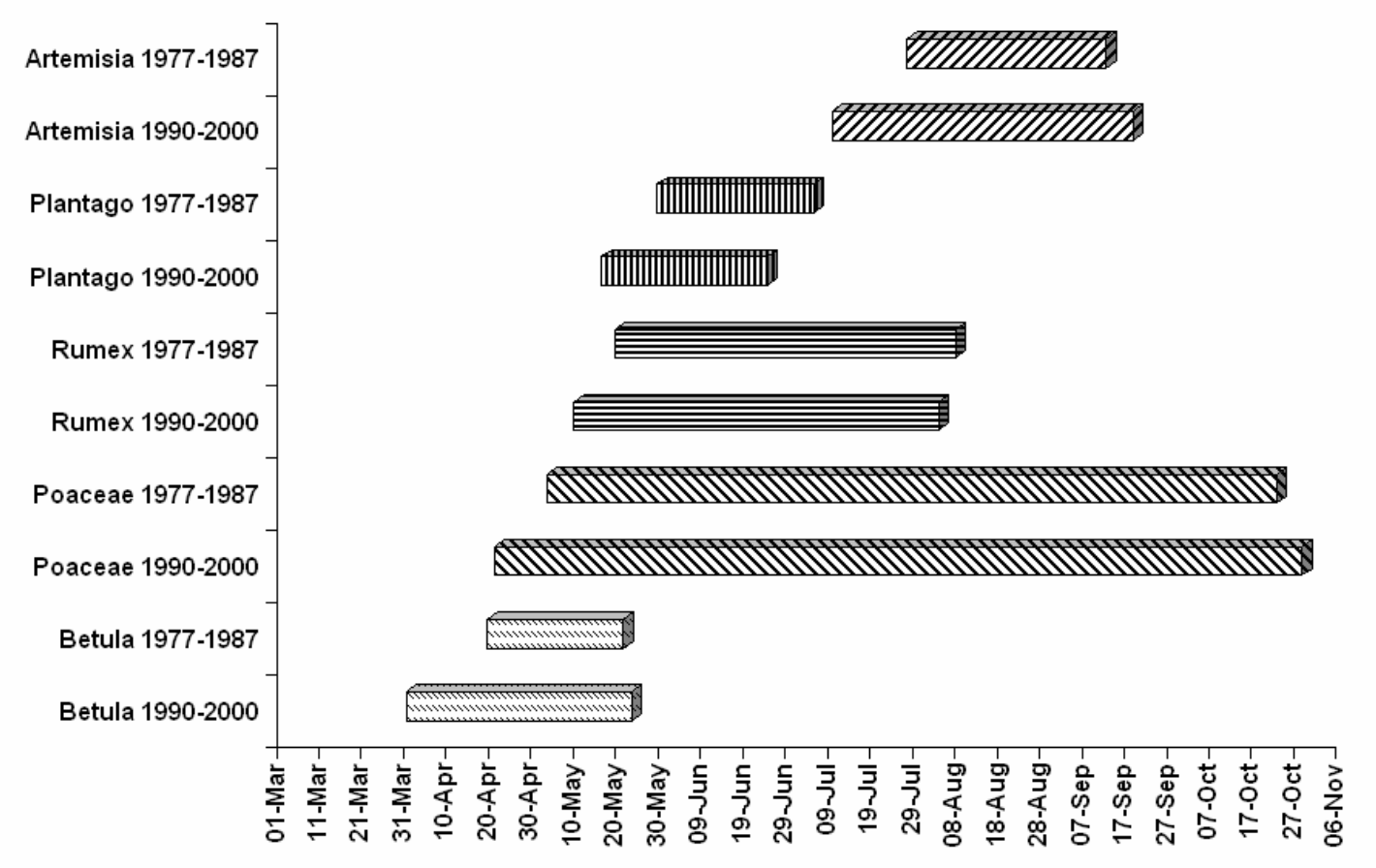

Figure 2. Comparison of the length of the flowering period of several plant species in the period before the steep increase of temperature at the end of the 1980s (1977-1987) and afterwards (1990-2000). The length is determined based on pollen data of the Leiden University Medical Centre, The Netherlands

There is increasing evidence to support an upward trend in the airborne-pollen counts of several common allergenic species (Frei and Leuschner 2000; Rasmussen 2002; Spieksma et al. 2003). Future climatic changes may further influence the flowering period, while pollen production is expected to increase. Doubling of the $\mathrm{CO}_{2}$ concentration in the atmosphere has resulted in a large increase $(61 \%)$ of the production of allergenic Ambrosia pollen in an experimental design (Wayne et al. 2002). Ambrosia is rare in The Netherlands, but this is likely to change. This species is advancing northwards from Southern Europe since the beginning of the 1990s, due to the same climatic changes (WHO et al. 2003).

\section{Prevention}

\section{Medical prevention strategies}

Given the large socioeconomic impact of hay fever, the increasing number of patients and the relation to other allergic disorders, there is an increasing need for the prevention of hay fever. Prevention encompasses any strategy that leads to a reduction of sensitization and/or mitigation of allergic complaints. This may be achieved by avoiding the contact to pollen allergens or by reducing the effect of the adjuvant environmental factors (Figure 1).

From a medical point of view, three strategies can be discerned on the level of the individual patient (UCB 1997). Primary prevention starts with a risk analysis at birth. Sensitization may be prevented in those groups at risk of developing an allergy by curtailing the risk factors. This calls for active avoidance of adverse adjuvant environmental factors and contact to potential allergens. Secondary prevention is applicable to those patients who have mild symptoms in early childhood. Sensitization 
may still be transient, and by curtailing the adjuvant environmental factors, administration of preventive medication and perhaps the application of immunotherapy, worsening of symptoms can be counteracted. Patients in need for tertiary prevention have an allergy that is already in a progressed stage. The progression towards more severe hay-fever symptoms and facilitation of the development of other allergic disorders, like asthma, may be avoided through proper medication and immunotherapy.

\section{Strategies to facilitate avoidance}

Prevention strategies that deal with the avoidance of pollen allergens call for active involvement of the patients themselves. Shortening the contact with outdoor air in periods in which the pollen concentration is highest, reduces the contact with allergenic pollen. This requires good communication towards patients to make them aware of the need and possibilities for avoidance. This also asks for reliable information on the presence of pollen. The hay-fever communications of the Leiden University Medical Centre give information on the risks of hay-fever complaints for particular days and hours of the day, and such services also exist in other countries. (http://www.polleninfo.org). Especially warm, dry and windy weather conditions favour high pollen concentrations, thereby creating bad circumstances for patients. The pollen concentrations are usually highest at the end of the afternoon and it is advisable to keep doors and windows closed under these conditions. It is, however, important to note that for example during the flowering season of birch, pollen concentrations are above threshold levels all day (Clot 2001). Allergic symptoms may thus appear at any time during the day. Patients and doctors in The Netherlands have the opportunity to view whether and where several pollen-producing species are flowering through the "Natuurkalender" website. This phenological overview was recently brought to use and is based on daily observations, made by volunteers throughout the country. In the near future the number of available species will be extended and flowering forecasts will be added. The website (http://www.natuurkalender.nl) also contains links to similar networks in other European countries, Canada and the USA.

Active avoidance of the allergenic pollen is accompanied by social restrictions, reducing both the acceptance and functionality of these prevention strategies. If patients would be monosensitized to one particular group of plants (trees, grasses or weeds), this would limit their freedom of movement only for a part of the year. However, many patients are polysensitized (Crimi et al. 1999; Mari, Wallner and Ferreira 2003) and experience symptoms during the tree, grasses as well as weed pollen seasons, which together may last as much as 9 months a year. The impact of avoidance strategies is also limited because pollen can easily penetrate buildings and may accumulate indoors (Fahlbusch et al. 2000). It is therefore important to investigate other mitigation strategies that focus on the living environment of patients.

\section{Strategies to reduce the allergenic load}

A decreased concentration of allergenic pollen or a reduced allergenicity of the pollen sources are potential strategies for mitigation. For this, it is important to know the origin of the pollen that causes the initial sensitization and leads to the majority of the complaints. This pollen may be of local origin or distributed by long-distance transport. In other words, does the sensitizing pollen originate from the ornamental birch tree down the street or the grass in your own garden, or does it originate from far away? It should be emphasized that pollen release causes a strong increase of the 
pollen concentration in the local air (Clot 2001) and that pollen counts are strongly influenced by the nearby presence of birch trees (Spieksma et al. 2003). Although a small fraction of the pollen may be distributed by long-distance transport, the majority of the pollen will end up near the source. These sources are heterogeneously distributed across the environment and large quantities of pollen can thus be avoided. A prevention strategy to decrease the amount of allergenic trees in the urban environment would be feasible by pursuing a goal-oriented policy with respect to the planting of trees. This is only possible to a certain extent, since many tree species are considered an integral part of the landscape and completely leaving out characteristic species would therefore impoverish the living environment.

This focuses our attention on those strategies that are oriented towards a reduction of the allergenicity of individual trees. This involves strategies that are directed towards the selection, within the existing natural variation, of trees that produce hypoallergenic or non-allergenic pollen, or produce strongly reduced amounts of pollen. Hypoallergenicity may either relate to hypoallergenic proteins, which lack the epitopes that are recognized by the human immune system, or to a reduced synthesis of allergenic proteins in the pollen. For example, the allergenic Bet $\mathrm{v} 1$ protein in birch pollen is a pathogenesis-related (PR-)10 protein (Breiteneder and Ebner 2000). PR-10 proteins are part of the protection mechanism against physiologically unfavourable conditions and a defence route against pathogens. The selection of plants that produce less allergenic proteins under these circumstances offers a possibility. Selective breeding may further enhance these characteristics. The potential consequences for the fitness of the plants are currently unknown. The expression of allergenic proteins can also be silenced through genetic modification. Knocking out the expression of allergenic plant genes has already been demonstrated for the Lol p 5 protein in ryegrass pollen (Bhalla, Swoboda and Singh 1999). Similar strategies can be developed for birch trees. Another strategy would be the selection for plants that are completely sterile or have male sterile flowers, which is a naturally occurring phenomenon in some plant species. It can be induced in other species, including birch, by genetic modification (Lemmetyinen, Keinonen and Sopanen 2004).

\section{Acceptability of prevention strategies}

Two of the prevention strategies presented in this paper deal with genetic modification as a mitigation or prevention strategy. Besides the public interest in the prevention of hay fever, both for social and economical reasons, there is also an interest for prevention without raising the public's concerns. Strategies that involve genetic modification are likely to receive some adverse reactions from the public, since DNA research is generally perceived as an unknown and moderately dreaded hazard (Slovic 1987). Societal acceptance of these strategies should therefore be considered during the process of development. Acceptance depends more on public reactions to specific applications, rather than on public attitudes towards the technology overall, and the public is thus inclined to accept or reject applications of technology on a case-to-case basis (Frewer, Howard and Shepherd 1997). Applications involving plants or micro-organism are in general more acceptable than those involving animals. To a lesser extent, medical applications are considered more necessary and thereby more acceptable than food-related applications (Frewer, Howard and Shepherd 1997).

Since the prevention strategies mentioned here involve genetic modification of allergenic plants, it can be hypothesized that these would be relatively acceptable (or relatively more acceptable than modification for other purposes). In addition, these 
applications may relieve medical complaints. However, when exposure to a risk is perceived as involuntary, it is regarded as more threatening than when an individual has a choice over personal exposure (Slovic 1987). Avoiding exposure would be very difficult to achieve in case of genetic modification of pollen-producing plants. This implies that, in theory, the induction of male sterility in plants would be the most acceptable genetic modification strategy. At the same time, some strategies that do not involve genetic modification also have side effects that may reduce their acceptability. For example, omitting characteristic tree species in the urban environment can be perceived as an 'unnatural' or impoverished state of the landscape. To determine the factors that affect risk perception is difficult without detailed empirical analyses, and further research is needed to examine public acceptance for mitigation and prevention strategies.

\section{Conclusion}

It is important to note that the aetiology of allergy progresses from a sensitization phase to a response phase. The largest benefits of prevention can be gained during the sensitization phase. One should prevent that potential patients come into contact with sensitizing levels of allergens. If this fails, relief of complaints can be achieved by minimizing the contact with these allergens. Prevention of contact demands for an active involvement of potential patients and good communication about the importance and possibilities for reducing the contact with allergenic pollen. It also demands for investments in innovative research, which focuses on the reduction of the allergenicity and amount of allergenic pollen in the patient's living environment. Acceptability of the mitigation and prevention strategies should be taken into consideration during this process.

\section{References}

Aberg, N., Hesselmar, B., Aberg, B., et al., 1995. Increase of asthma, allergic rhinitis and eczema in Swedish schoolchildren between 1979 and 1991. Clinical and Experimental Allergy, 25 (9), 815-819.

Alm, J.S., Lilja, G., Pershagen, G., et al., 1997. Early BCG vaccination and development of atopy. Lancet, 350 (9075), 400-403.

Alm, J.S., Swartz, J., Lilja, G., et al., 1999. Atopy in children of families with an anthroposophic lifestyle. Lancet, 353 (9163), 1485-1488.

Asero, R., Mistrello, G., Roncarolo, D., et al., 2000. Detection of allergens in plantain (Plantago lanceolata) pollen. Allergy, 55 (11), 1059-1062.

Bhalla, P.L., Swoboda, I. and Singh, M.B., 1999. Antisense-mediated silencing of a gene encoding a major ryegrass pollen allergen. Proceedings of the National Academy of Sciences of the United States of America, 96 (20), 11676-11680.

Bohle, B., Radakovics, A., Jahn-Schmid, B., et al., 2003. Bet v 1, the major birch pollen allergen, initiates sensitization to Api g 1, the major allergen in celery: evidence at the T cell level. European Journal of Immunology, 33 (12), 33033310.

Bond, J.F., Segal, D.B., Yu, X.B., et al., 1993. Human IgE reactivity to purified recombinant and native grass allergens. Journal of Allergy and Clinical Immunology, 91 (1), 339. 
Breiteneder, H. and Ebner, C., 2000. Molecular and biochemical classification of plant-derived food allergens. Journal of Allergy and Clinical Immunology, 106 (1 Pt 1), 27-36.

Breiteneder, H., Ferreira, F., Hoffmann-Sommergruber, K., et al., 1993. Four recombinant isoforms of Cor a I, the major allergen of hazel pollen, show different IgE-binding properties. European Journal of Biochemistry, 212 (2), 355-362.

Breiteneder, H., Ferreira, F., Reikerstorfer, A., et al., 1992. Complementary DNA cloning and expression in Escherichia coli of Aln $\mathrm{g}$ I, the major allergen in pollen of alder (Alnus glutinosa). Journal of Allergy and Clinical Immunology, 90 (6 Pt. 1), 909-917.

Breiteneder, H., Pettenburger, K., Bito, A., et al., 1989. The gene coding for the major birch pollen allergen Betv1, is highly homologous to a pea disease resistance response gene. Embo Journal, 8 (7), 1935-1938.

Brunekreef, B., Hoek, G., Fischer, P., et al., 2000. Relation between airborne pollen concentrations and daily cardiovascular and respiratory-disease mortality. Lancet, 355 (9214), 1517-1518.

Clot, B., 2001. Airborne birch pollen in Neuchâtel (Switzerland): onset, peak and daily patterns. Aerobiologia, 17 (1), 25-29.

Crimi, P., Boidi, M., Minale, P., et al., 1999. Differences in prevalence of allergic sensitization in urban and rural school children. Annals of Allergy, Asthma and Immunology, 83 (3), 252-256.

D'Amato, G., Spieksma, F.T., Liccardi, G., et al., 1998. Pollen-related allergy in Europe. Allergy, 53 (6), 567-578.

Fahlbusch, B., Hornung, D., Heinrich, J., et al., 2000. Quantification of group 5 grass pollen allergens in house dust. Clinical and Experimental Allergy, 30 (11), 1645-1652.

Ferreira, F., Hawranek, T., Gruber, P., et al., 2004. Allergic cross-reactivity: from gene to the clinic. Allergy, 59 (3), 243-267.

Frei, T. and Leuschner, R.M., 2000. A change from grass pollen induced allergy to tree pollen induced allergy: 30 years of pollen observation in Switzerland. Aerobiologia, 16 (3/4), 407-416.

Frewer, L.J., Howard, C. and Shepherd, R., 1997. Public concerns in the United Kingdom about general and specific applications of genetic engineering: risk, benefit, and ethics. Science, Technology and Human Values, 22 (1), 98-124.

Fritsch, R., Bohle, B., Vollmann, U., et al., 1998. Bet v 1, the major birch pollen allergen, and Mal d 1, the major apple allergen, cross-react at the level of allergen-specific T helper cells. Journal of Allergy and Clinical Immunology, 102 (4 Pt. 1), 679-686.

Heiss, S., Fischer, S., Muller, W.D., et al., 1996. Identification of a $60 \mathrm{kd}$ crossreactive allergen in pollen and plant-derived food. Journal of Allergy and Clinical Immunology, 98 (5 Pt. 1), 938-947.

Hirschwehr, R., Heppner, C., Spitzauer, S., et al., 1998. Identification of common allergenic structures in mugwort and ragweed pollen. Journal of Allergy and Clinical Immunology, 101 (2 Pt. 1), 196-206.

Hirschwehr, R., Valenta, R., Ebner, C., et al., 1992. Identification of common allergenic structures in hazel pollen and hazelnuts: a possible explanation for sensitivity to hazelnuts in patients allergic to tree pollen. Journal of Allergy and Clinical Immunology, 90 (6 Pt. 1), 927-936. 
Hjern, A., Hedberg, A., Haglund, B., et al., 2001. Does tobacco smoke prevent atopic disorders? A study of two generations of Swedish residents. Clinical and Experimental Allergy, 31 (6), 908-914.

Jõgi, R., Janson, C., Björnsson, E., et al., 1998. Atopy and allergic disorders among adults in Tartu, Estonia compared with Uppsala, Sweden. Clinical and Experimental Allergy, 28 (9), 1072-1080.

Karamloo, F., Wangorsch, A., Kasahara, H., et al., 2001. Phenylcoumaran benzylic ether and isoflavonoid reductases are a new class of cross-reactive allergens in birch pollen, fruits and vegetables. European Journal of Biochemistry, 268 (20), 5310-5320.

Krause, T.G., Koch, A., Poulsen, L.K., et al., 2002. Atopic sensitization among children in an arctic environment. Clinical and Experimental Allergy, 32 (3), 367-372.

Kulig, M., Klettke, U., Wahn, V., et al., 2000. Development of seasonal allergic rhinitis during the first 7 years of life. Journal of Allergy and Clinical Immunology, 106 (5), 832-839.

Latalowa, M., Mietus, M. and Uruska, A., 2002. Seasonal variations in the atmospheric Betula pollen count in Gdánsk (southern Baltic coast) in relation to meteorological parameters. Aerobiologia, 18 (1), 33-43.

Lee, Y.L., Shaw, C.K., Su, H.J., et al., 2003. Climate, traffic-related air pollutants and allergic rhinitis prevalence in middle-school children in Taiwan. European Respiratory Journal, 21 (6), 964-970.

Lemmetyinen, J., Keinonen, K. and Sopanen, T., 2004. Prevention of the flowering of a tree, silver birch. Molecular Breeding, 13 (3), 243-249.

Lüttkopf, D., Müller, U., Skov, P.S., et al., 2002. Comparison of four variants of a major allergen in hazelnut (Corylus avellana) Cor a 1.04 with the major hazel pollen allergen Cor a 1.01. Molecular Immunology, 38 (7), 515-25.

Mari, A., Wallner, M. and Ferreira, F., 2003. Fagales pollen sensitization in a birchfree area: a respiratory cohort survey using Fagales pollen extracts and birch recombinant allergens (rBet v 1, rBet v 2, rBet v 4). Clinical and Experimental Allergy, 33 (10), 1419-1428.

Meltzer, E.O., 2001. Quality of life in adults and children with allergic rhinitis. Journal of Allergy and Clinical Immunology, 108 (1 Suppl.), S45-S53.

Miralles, J.C., Caravaca, F., Guillen, F., et al., 2002. Cross-reactivity between Platanus pollen and vegetables. Allergy, 57 (2), 146-149.

Portengen, L., Sigsgaard, T., Omland, Ø., et al., 2002. Low prevalence of atopy in young Danish farmers and farming students born and raised on a farm. Clinical and Experimental Allergy, 32 (2), 247-253.

Rasmussen, A., 2002. The effects of climate change on the birch pollen season in Denmark. Aerobiologia, 18 (3/4), 253-265.

Riedler, J., Eder, W., Oberfeld, G., et al., 2000. Austrian children living on a farm have less hay fever, asthma and allergic sensitization. Clinical and Experimental Allergy, 30 (2), 194-200.

Rönmark, E., Perzanowski, M., Platts-Mills, T., et al., 2003. Four-year incidence of allergic sensitization among schoolchildren in a community where allergy to cat and dog dominates sensitization: report from the Obstructive Lung Disease in Northern Sweden Study Group. Journal of Allergy and Clinical Immunology, 112 (4), 747-754. 
Rossi, R. E., Monasterolo, G. and Monasterolo, S., 2003. Detection of specific IgE antibodies in the sera of patients allergic to birch pollen using recombinant allergens Bet $\mathrm{v} 1$, Bet $\mathrm{v} 2$, Bet $\mathrm{v}$ 4: evaluation of different $\operatorname{IgE}$ reactivity profiles. Allergy, 58 (9), 929-932.

Saarinen, U.M. and Kajosaari, M., 1995. Breastfeeding as prophylaxis against atopic disease: prospective follow-up study until 17 years old. Lancet, 346 (8982), 1065-1069.

Scheurer, S., Son, D.Y., Boehm, M., et al., 1999. Cross-reactivity and epitope analysis of Pru a 1, the major cherry allergen. Molecular Immunology, 36 (3), 155-167.

Schoenwetter, W.F., Dupclay Jr., L., Appajosyula, S., et al., 2004. Economic impact and quality-of-life burden of allergic rhinitis. Current Medical Research and Opinion, 20 (3), 305-317.

Silvestri, M., Oddera, S., Rossi, G.A., et al., 1996. Sensitization to airborne allergens in children with respiratory symptoms. Annals of Allergy, Asthma and Immunology, 76 (3), 239-244.

Slovic, P., 1987. Perception of risk. Science, 236 (4799), 280-285.

Spieksma, F.T.M., Corden, J.M., Detandt, M., et al., 2003. Quantitative trends in annual totals of five common airborne pollen types (Betula, Quercus, Poaceae, Urtica, and Artemisia), at five pollen-monitoring stations in western Europe. Aerobiologia, 19 (3/4), 171-184.

Strachan, D.P., 1989. Hay fever, hygiene, and household size. British Medical Journal, 299 (6710), 1259-1260.

UCB, 1997. European allergy white paper. The UCB Institute of Allergy. [http://www.theucbinstituteofallergy.ucb.be/WhitePaper/]

Van Vliet, A.J.H., Overeem, A., De Groot, R.S., et al., 2002. The influence of temperature and climate change on the timing of pollen release in the Netherlands. International Journal of Climatology, 22 (14), 1757-1767.

Von Mutius, E., Martinez, F.D., Fritzsch, C., et al., 1994. Skin test reactivity and number of siblings. British Medical Journal, 308 (6930), 692-695.

Wayne, P., Foster, S., Connolly, J., et al., 2002. Production of allergenic pollen by ragweed (Ambrosia artemisiifolia L.) is increased in CO2-enriched atmospheres. Annals of Allergy, Asthma and Immunology, 88 (3), 279-282.

Wensing, M., Akkerdaas, J.H., van Leeuwen, W.A., et al., 2002. IgE to Bet v 1 and profilin: cross-reactivity patterns and clinical relevance. Journal of Allergy and Clinical Immunology, 110 (3), 435-442.

Weryszko-Chmielewska, E., Puc, M. and Rapiejko, P., 2001. Comparative analysis of pollen counts of Corylus, Alnus and Betula in Szczecin, Warsaw and Lublin (2000-2001). Annals of Agricultural and Environmental Medicine, 8 (2), 235240.

Westphal, S., Kempf, W., Foetisch, K., et al., 2004. Tomato profilin Lyc e 1: IgE cross-reactivity and allergenic potency. Allergy, 59 (5), 526-532.

WHO, EPN, ICIS, et al., 2003. Phenology and human health: allergic disorders: report of a WHO meeting, Rome, Italy, 16-17 January 2003. WHO Regional Office for Europe, Copenhagen. [http://www.euro.who.int/document/e79129.pdf]

Wüthrich, B., Schindler, C., Leuenberger, P., et al., 1995. Prevalence of atopy and pollinosis in the adult population of Switzerland (SAPALDIA study). Swiss Study on Air Pollution and Lung Diseases in Adults. International Archives of Allergy and Immunology, 106 (2), 149-156. 
Yazdanbakhsh, M., Kremsner, P.G. and Van Ree, R., 2002. Allergy, parasites, and the hygiene hypothesis. Science, 296 (5567), 490-494. 